\title{
Narcissistic rage: The Achilles' heel of the patient with chronic physical illness
}

\author{
This article was published in the following Dove Press journal: \\ Patient Preference and Adherence \\ 7 August 2009 \\ Number of times this article has been viewed
}

\author{
Thomas Hyphantis' \\ Augustina Almyroudi' \\ Vassiliki Paika' \\ Panagiota Goulia' \\ Konstantinos Arvanitakis ${ }^{2,3}$ \\ 'Department of Psychiatry, Medical \\ School, University of loannina, \\ loannina, Greece; ${ }^{2}$ Canadian Institute \\ of Psychoanalysis, McGill University, \\ Montreal, Canada; ${ }^{3}$ Departments \\ of Philosophy and Psychiatry, McGill \\ University Health Centre, Montreal, \\ Canada
}

Correspondence: Thomas Hyphantis University of loannina, Medical School, Department of Psychiatry, loannina 45 I I0, Greece,

Tel +30265I097322

Email tyfantis@cc.uoi.gr
Abstract: Based on the psychoanalytic reading of Homer's Iliad whose principal theme is "Achilles' rage" (the semi-mortal hero invulnerable in all of his body except for his heel, hence "Achilles' heel" has come to mean a person's principal weakness), we aimed to assess whether "narcissistic rage" has an impact on several psychosocial variables in patients with severe physical illness across time. In 878 patients with cancer, rheumatological diseases, multiple sclerosis, inflammatory bowel disease, and glaucoma, we assessed psychological distress (SCL-90 and GHQ-28), quality of life (WHOQOL-BREF), interpersonal difficulties (IIP-40), hostility (HDHQ), and defense styles (DSQ). Narcissistic rage comprised DSQ “omnipotence" and HDHQ "extraverted hostility". Hierarchical multiple regressions analyses were performed. We showed that, in patients with disease duration less than one year, narcissistic rage had a minor impact on psychosocial variables studied, indicating that the rage was rather part of a "normal" mourning process. On the contrary, in patients with longer disease duration, increased rates of narcissistic rage had a great impact on all outcome variables, and the opposite was true for patients with low rates of narcissistic rage, indicating that narcissistic rage constitutes actually an "Achilles' Heel” for patients with long-term physical illness. These findings may have important clinical implications.

Keywords: consultation-liaison psychiatry, psychosomatics, narcissism, physical illness, quality of life, psychological distress, personality

"... surely all this is not without meaning. And still deeper the meaning of that story of Narcissus, who because he could not grasp the tormenting, mild image he saw in the fountain, plunged into it and was drowned.... It is the image of the ungraspable phantom of life; and this is the key to it all"

$$
\text { -Herman Melville, Moby Dick or the Whale (p. 4) }{ }^{1}
$$

The term "Narcissism" has been coined by Freud, who initially described narcissism as a developmental stage between self-love and object-love, during which one takes oneself and one's own body as the love object. ${ }^{2,3}$ Three years later, in his paper "On Narcissism," Freud elaborated this new concept by drawing a distinction between ego libido and object libido. ${ }^{4}$ At that time, Freud alluded to all facets of narcissism except aggression and rage. ${ }^{3}$ In 1915, Freud acknowledged a formal polarity between love and hate, and he gave independent recognition to an aggressive impulse. ${ }^{3,5}$ Overall, as Otto Kernberg noted, ${ }^{6}$ "Freud explores narcissism as a phase of psychic development, as a crucial aspect of normal love life, as a central dynamic of several types of 
psychopathology, as the origin of the ego-ideal, and - by way of the ego ideal - an aspect of mass psychology" (p. 131).

Freud's exploration into narcissism was central to the development of a number of analytic theories on narcissism, as the perspectives of Melanie Klein (including projective identification of hostility and goodness, leading to splitting of hatred and rage, and idealization; envy, and the paranoid/schizoid and depressive positions and their relations to objects) and Kernberg's recognition that the defense of splitting (ie, the separating of positive and negative affectively laden images of oneself) is a central feature of narcissistic disturbance. ${ }^{6-8}$ Regarding rage, it has been suggested that Freud's first formulations of what he later called aggression were closer to the current concepts of narcissistic rage. ${ }^{9}$

"Narcissistic rage" is a clinical entity defined by Kohut $^{10}$ in The Analysis of the Self, ${ }^{11}$ who placed it into the context of the clinical theory of the self. Actually, self psychology is the product of Kohut's conceptualization of narcissism. ${ }^{9}$ Kohut calls the attention to a common, everyday phenomenon-the thirst for revenge; its tragic consequences have inspired some of the most gripping literature of our civilization. The paradigm might well be Captain Ahab in Melville's Moby Dick. ${ }^{9}$ As Terman has pointed out in his exceptional paper, ${ }^{9}$ the thirst for revenge is reactive; it is provoked by some injury to self-esteem - a narcissistic injury such as contempt, ridicule, conspicuous defeat, or events which in any case are experienced as such by the injured party. Ahab, for example, was in a relentless pursuit of the whale that had taken his leg. Kohut characterizes this rage as a reaction to the frustration of the omnipotence of the grandiose self.

According to the aforementioned theoretical basis, the development of a severe physical illness might also be experienced as an injury to self-esteem and may well serve as a stimulus for the frustration of the omnipotence of the "grandiose self", which in turn fires narcissistic rage, in the same way Ahab's taken leg fires his relentless pursuit. In this way narcissistic rage might be involved in the process of a physical illness.

As Terman ${ }^{9}$ pointed out, "the gist of Kohut's position is that one cannot address oneself to the rage per se, but must deal with the archaic narcissistic matrix out of which it arises. That is, one must try to understand the way in which the archaic self is again damaged and in what the original damage consisted; then there will be a shift of such aggression in the service of realistic ambition. Kohut notes that the individual's increased capacity for empathy for his potential offenders may be a more certain sign of integration and repair of the damaged self. Of course, the development of such empathy could not take place without significant changes in the self, and hence the matrix out of which the rage arises is destroyed - or transformed".

Patients with severe chronic illness confront this challenge, ie, they have to proceed with a number of significant changes in the self in order to deal with the consequences of the disease and to avoid further deterioration, and they also have to shift the aggression produced by the loses due to the disease in the service of realistic ambition (survival and maintenance of quality of life). In this way Kohut's conceptualization of narcissism might be relevant when considering illness, and this was the reason for choosing this particular theory, among all other psychoanalytic theories on narcissism, for discussion in the present study.

A description of such a "shift" of the aggression produced by the narcissistic rage, a "transformation" which resulted in integration and repair of the damaged self through the individual's capacity for empathy for his potential offenders, is described in a recently published psychoanalytic reading of Homer's Iliad by Arvanitakis. ${ }^{12}$ The basis for the examination of the manner that makes such a transition feasible was Achilles' transition from narcissistic rage to a capacity for compassion and concern.

\section{Achilles' heel and transition}

Achilles was a Greek hero of the Trojan War, the greatest warrior of Homer's Iliad. Achilles was semi-immortal, invulnerable in all of his body except for his heel. Since he died due to a poisoned arrow shot into his heel, the "Achilles' heel" has come to mean a person's principal weakness.

Iliad's initial word, $\mu \tilde{n} v ı \varsigma$ (mēnis - wrath, rage, fury), establishes the Iliad's principal theme: The Wrath of Achilles, ${ }^{13}$ which emerges when he loses his prize, the fair-cheeked Vriseis, ${ }^{14}$ to a man more powerful than him (King Agamemnon). His excessive narcissism suffers a decisive blow. Rigid as he is, unable to accept a compromise and perceiving himself as all-powerful and grand, withdraws from the battlefield. Now, the war is turning against the Achaeans. Achilles does not change his stance, despite the heavy casualties suffered by his comrades. Patroclus, his beloved friend, begs Achilles to let him wear his armor and join the battle. Achilles is finally persuaded. Patroclus (dressed as Achilles) is killed by Hector. Hector wears Achilles' armor. With furious anger Achilles joins the battle to avenge the death of Patroclus. He kills Hector (who is dressed as Achilles) and drags his 
body behind his chariot. He is aware that his own death is approaching: Achilles had been repeatedly told that his life would be short; Troy would only fall after his death, after he would be shot into his heel. Now, however, with Patroclus and Hector - dressed as Achilles - dead, the future is already past. Symbolically, Achilles is already dead! Priam, the elderly king, sets off to claim back the body of his son, Hector. Priam arrives at Achilles' tent and kneels before him. The two mortal enemies stare at each other. Priam expresses his grief. And then, Achilles, "mercifully", touches the old king's hand tenderly, helps him to stand up and offers him a seat. He orders the slaves to wash and to embalm Hector's body, and Achilles himself lifts Hector's body and places it on the hearse, he himself initiating Hector's funeral ceremony.

\section{From narcissistic rage to compassion and integration}

It has been suggested that the beginning of Achilles' "transition" is triggered by the death of Patroclus. ${ }^{12}$ It is at that moment that Achilles realizes his true nature, his limits and mortality, with the insinuation of his own death (Patroclus was dressed "as Achilles"). This is the fact that leads him to his own personal "reversal" during his meeting with Priam.

In these rhapsodies, all three elements that make up a tragic plot are present: reversal (reversal of the situation), recognition (in other words, a new knowledge), and suffering (pathos). ${ }^{12}$ It could be suggested, however, that the development of a severe physical disease might also shape another similar "tragic plot": it involves a reversal, since it reverses a situation (health), a recognition (a new knowledge - the disease - or a "reminder" of the mortality), and suffering (pathos, that is, pain).

The appearance of a severe physical disease reverses health status, frustrates the individual's self and omnipotence, and triggers narcissistic rage. The patient, like Achilles, initially withdraws from the "battlefield", frustrated and "depressed". During the progress of time and facing the new situation, the patient starts to recognize his/her own "destiny". The doctors' efforts, the exhausting laboratory tests, the therapeutic interventions, all serve as "reminders" of his/her mortal nature. And there is suffering and pain. If the patient is able to work through his/her rage and to link his/her past youthful, omnipotent self-image with the new more realistic image of the self, an integration and compassion may be achieved, with time being the catalyst of this process. This capacity will vary in accordance with the patient's ego strength, defensive style, hostility and quality of his/her relations. In a Kleinian perspective, the capacity to integrate a new and more realistic self-image will depend on the degree to which the individual has been able to work through depressive anxieties and move (metabasis) from the paranoid-schizoid position to the depressive position. ${ }^{12}$ Mourning for the omnipotent self plays a major role here. Prognosis will, indeed, depend on this. On the contrary, in the cases where enmity persists, the consequences can be disastrous. We aimed here to empirically confirm this postulation. The aim of the present study was to assess the impact of narcissistic rage on psychological adaptation over time in patients with severe physical illness.

\section{Methods}

\section{Participants}

The study design was cross-sectional. The sample comprised 878 patients with severe chronic physical illness, namely colorectal cancer, rheumatoid arthritis, systemic lupus erythematosus, systemic sclerosis (scleroderma), Sjögren's syndrome, multiple sclerosis, inflammatory bowel disease, and glaucoma. The patients were attending a respective follow-up clinic at the oncology, rheumatology, neurology, gastroenterology, and ophthalmology departments of the University General Hospital of Ioannina, Greece. The hospital provides secondary and tertiary care for a general population of 350,000 people.

Diagnosis of colorectal cancer was confirmed based on positive biopsy for cancer cells, after colonoscopy. ${ }^{15,16}$ Diagnoses of rheumatological diseases were confirmed based on the respective recommended criteria. ${ }^{17-19}$ Diagnosis of inflammatory bowel disease was confirmed based

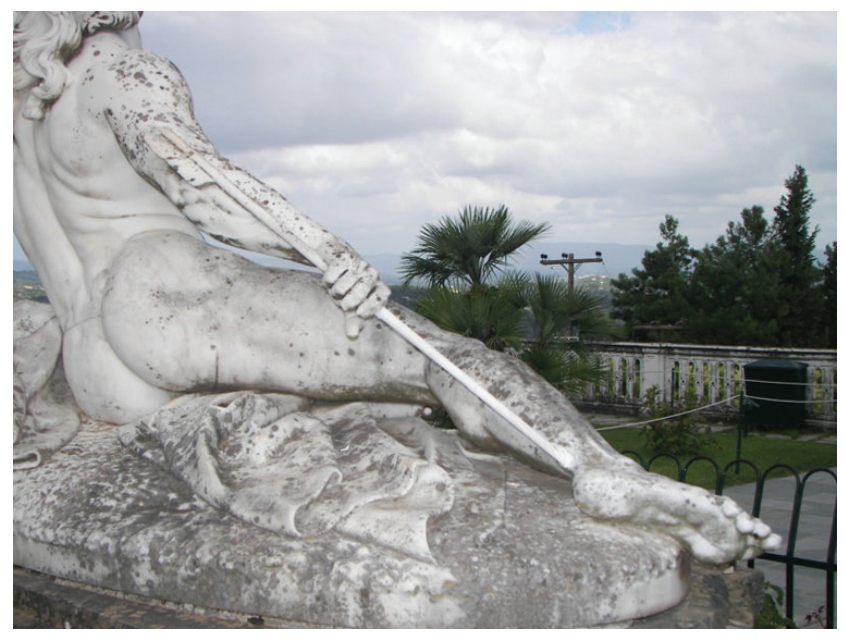

Figure I Dying Achilles at Achilleion, Corfu. Sculptor: Ernst Herter, 1884. 
on clinical, endoscopic, radiological, and histological evaluation. Diagnosis of multiple sclerosis was based on recent consensus criteria. ${ }^{20}$ Glaucoma patients demonstrated typical glaucomatous visual field loss and glaucomatous optic nerve cupping with open, normal appearing angles. ${ }^{21}$ Exclusion criteria were inability to read and write Greek, history of psychotic illness, current alcohol and/or drug abuse or dementia.

Out of 316 invited cancer patients, 247 patients were eligible and 162 agreed to participate in the study (response rate: $65.6 \%$ ). Out of 524 invited patients with rheumatological diseases, 427 were eligible and 320 (response rate: $74.8 \%$ ) agreed to participate in the study (168 with rheumatoid arthritis, 56 with systemic lupus erythematosus, 56 with systemic sclerosis, and 40 with Sjögren's syndrome). Out of 264 invited patients with inflammatory bowel disease, 227 patients were eligible, and 185 agreed to participate in the study (response rate: $81.5 \%$ ). Finally, out of 136 invited glaucoma patients, 128 were eligible and 100 agreed to participate (response rate: $78.1 \%$ ). Among eligible patients, no statistical significant differences in major demographic characteristics were found between the participants' and nonparticipants' groups. After full explanation of the study, signed informed consent was obtained from all participants. All the procedures followed were in accordance with the ethical standards on human experimentation (World Medical Association Helsinki Declaration) and were approved by the Ioannina University General Hospital's responsible ethical committee (No 20/14.01.2004 and No 11/7.11.2006).

\section{Measures}

Clinical data were obtained by reviewing patients' records using a standardized data collection form. The following questionnaires were administered along with a request for demographic information:

\section{Psychological distress}

Psychological distress was measured using the General Health Questionnaire (GHQ-28) and the Symptom Distress Checklist-90-R (SCL-90-R). The GHQ-2822 consists of 28 items belonging to four clusters: (a) somatic symptoms of depression; (b) anxiety and insomnia; (c) social dysfunction; and (d) depressive feelings. It has been widely used in medical patients and it has also been standardized for the Greek population. ${ }^{23}$ The SCL-90-R is a 90 -item multidimensional self-report symptom inventory designed to measure a wide range of psychopathological symptoms in psychiatric and medical patients. ${ }^{24}$ It also estimates the Global Severity Index
(GSI) designed to measure overall psychological distress and it has been also standardized for the Greek population. ${ }^{25}$

\section{Difficulties in interpersonal relationships}

Difficulties in interpersonal relationships were assessed using the Inventory of Interpersonal Problems (IIP-40). ${ }^{26}$ It is a 40 -item shortened version of the original 127 item questionnaire. ${ }^{27}$ IIP-40 comprises eight subscales, each of five items, ranging from "lower neutral" to "lower distant", which conform to the eight octant positions within Birtchnell's interpersonal octagon, a version of interpersonal theory. Birtchnell's "interpersonal octagon" has the virtue both of integrating with evolutionary theory and of sitting comfortably with a psychodynamic model. The subscales have demonstrated good face validity and acceptable reliability. ${ }^{26}$

\section{Hostility}

Hostility was assessed using the Hostility and Direction of Hostility Questionnaire (HDHQ) ${ }^{28}$ It provides a measure of hostility manifestation that reflects an attitudinal personality trait and shows the participant's reaction to frustrating occurrences. The HDHQ is designed to sample a wide range of possible manifestations of aggression and is composed of three subscales measuring extrapunitive manifestations of hostility and two subscales measuring manifestations of intropunitive hostility. The HDHQ has been widely used within the general Greek population as well as with medical patients. ${ }^{29-31}$

\section{Defense mechanisms}

Ego mechanisms of defense are defined as "automatic psychological processes that protect the individual against anxiety and from the awareness of internal or external dangers or stressors, mediating the individual's reactions to emotional conflicts and to internal or external stressors" ${ }^{32}$ To assess defense mechanisms we used the Defense Style Questionnaire (DSQ) which is designed to estimate behaviour suggestive of 25 ego defense mechanisms and four defense styles, namely, "maladaptive action," "image distorting," "self-sacrificing," and "adaptive" styles. ${ }^{33}$ DSQ has been also widely used with Greek medical patients, ${ }^{30,31,34}$ and the standardization results so far indicate that the Greek version of DSQ shares, for the most part, the same properties as the original. ${ }^{30}$

\section{Narcissistic rage}

Since our hypothesis is mainly focused on the effects of "narcissistic rage", a new variable was created in an effort to empirically simulate this concept, based on components of the DSQ and HDHQ. Thus, "omnipotence", as assessed 
by DSQ, and "extrapunitive hostility", as assessed by HDHQ were combined, after proper statistical adaptation of the scores derived from the two different scales. "Omnipotence" is a defense mechanism by which the individual deals with emotional conflict or internal or external stressors by feeling or acting as if he or she possesses special powers or abilities and is superior to others. ${ }^{33}$ "Extrapunitive hostility" is a dynamic concept representing the direction of aggression and hostility which is turned against others. ${ }^{28}$ Thus, the new variable included the DSQ statements assessing "omnipotence" (eg, I am superior to most people I know. I often feel superior to people I'm with. I ignore danger as if I were Superman. I pride myself on my ability to cut people down to size. I have got special talents that allow me to go through life with no problems), as well as the HDHQ statements assessing "extrapunitive hostility" (ie, urges to act out hostility, criticism of others, and projected delusional hostility). The internal consistency coefficient (Cronbach's alpha) for "narcissistic rage" obtained from the present sample was 0.93 , a highly acceptable value with regard to the internal structure of the new scale.

\section{Health-related quality of life}

Health-related quality of life (HRQOL) was assessed by means of the World Health Organization Quality of Life Instrument, Short-Form (WHOQOL-BREF). ${ }^{35,36}$ The WHOQOL-BREF assesses four domains of HRQOL: physical, psychological, social relationships and environment HRQOL. Each item is rated on a five-point Likert interval scale and the scores are transformed on a scale from 0 to 100 . A higher score indicates better HRQOL. Domain scores produced by the WHOQOL-BREF correlate highly with the longer version of the instrument (WHOQOL-100) domain scores; WHOQOL-BREF demonstrated good discriminant validity, content validity, internal consistency and test-retest reliability, providing a valid and reliable alternative to WHOQOL-100. ${ }^{35}$ In addition, data obtained from a survey of adults carried out in 23 countries including Greece showed that WHOQOL-BREF is a cross-culturally valid assessment of HRQOL. ${ }^{36}$ WHOQOL-BREF has been found to have adequate test-retest reliability, internal consistency and factor structure in people with medical diseases. ${ }^{37}$ The Greek version of the WHOQOL-BREF ${ }^{36,38}$ has been used previously as an outcome measure of HRQOL. ${ }^{31,34}$

\section{Statistical analysis}

All the statistical analyses were performed using the Statistical Package for the Social Sciences (SPSS) (version
15.0 for Windows; SPSS Inc., Chicago, IL, USA). Summary statistics for all variables were calculated. Normality was tested by the Kolmogorov-Smirnov test. ${ }^{39}$

Pearson correlation analyses were conducted to assess the relationship of "narcissistic rage" with all outcome variables in patients with disease duration less than one year and those with disease duration more than one year. ${ }^{39}$

To test whether patients categorized as presenting "high narcissistic rage" scores differ from patients categorized as presenting "low narcissistic rage" scores with regard to our outcome variables, we categorized patients' "narcissistic rage" scores in three groups: high, medium, and low. We used a strict criterion for dividing subgroups: ${ }^{30,33}$ if a subject's score on "narcissistic rage" was $0.5 \mathrm{SD}$ above the mean we considered that this subject excessively exhibited that trait, and the patient was regarded as presenting "high narcissistic rage". Those patients whose score was $0.5 \mathrm{SD}$ below the mean were regarded as presenting "low narcissistic rage".

In order to test whether patients with "high narcissistic rage" differ from patients with "low narcissistic rage" with respect to outcome variables across time ( $<1$ year and $>1$ year), we contrasted in each separate time-period the groups of participants on the "narcissistic rage" using univariate ANCOVA adjusted for age, gender, and educational level.

Two hierarchical models of multiple regression analyses were next performed. The dependent variable was the mean score of interpersonal difficulties as measured by the IIP- 40 . Selection of independent variables was based on the results of the previous univariate analyses. The demographic variables were entered in step 1, the "narcissistic rage" in step 2, followed by the SCL-90 Global Severity Index entered in model 3. The model of hierarchical analyses served also as a mediation analysis to test whether psychological distress mediates the relationships between independent variables and interpersonal difficulties that were significant in the previous model (step 2). To fulfil the requirements of mediation according to the method of Baron and Kenny, ${ }^{40}$ the following three associations should be significant in multiple regression equations: 1) independent variable and outcome variable (interpersonal difficulties), 2) independent variable and mediating variable (SCL-90 Global Severity Index), and 3) mediating variable and outcome. If these criteria were fulfilled, we added in the final step of each hierarchical regression analysis the SCL-90 global severity index and noted whether this rendered the previous associations between independent variables and interpersonal difficulties nonsignificant. The magnitude of the $\mathrm{R}^{2}$ change at each step of the hierarchical regression analysis was used to determine 
the variance explained by each set of variables. Colinearity between independent variables was tested based on variance inflation factors (VIF) and tolerances for individual variables. $^{41}$

\section{Results}

\section{Patient's characteristics}

The patients' demographic profile and the basic disease parameters are presented in Table 1. As shown in this table, 196 patients had a short-term medical disease and 670 patients had a long-term disease, with a mean duration of 9.8 years. Mean duration rates were: for cancer, 1.6 years (SD, 9.5); rheumatoid arthritis, 19.9 (SD, 8.5) years; systemic lupus erythematosus, 12.1 (SD, 8.1) years; systemic sclerosis, 15.4 (SD, 12.1) years; inflammatory bowel disease, 8.0 (SD, 3.1) years; multiple sclerosis, $8.2(\mathrm{SD}, 5.9)$ years and glaucoma, 1.6 (SD, 2.1) years. In the entire sample, 309 patients $(37.8 \%)$ were classified as belonging to the "low narcissistic rage" sample, and 319 patients (39.1\%) were classified as belonging to the "high narcissistic rage" sample. Eighty-two patients $(41.8 \%)$ among those with disease duration less than one year and 237 (35.4\%) among those with disease duration

Table I Patients' demographic profile and disease parameters $(\mathrm{N}=878)$

\begin{tabular}{ll}
\hline Demographics & \\
Age [median, mean \pm SD] & $56,53.7 \pm 15.9$ \\
Education & \\
Primary school & $459(52.3 \%)$ \\
High school & $254(28.9 \%)$ \\
College/University & $165(18.8 \%)$ \\
Gender & \\
Female & $499(56.8 \%)$ \\
Male & $379(43.1 \%)$ \\
Disease duration & \\
$<$ I year (short-term disease) & $196(22.6 \%)$ \\
$>$ I year (long-term disease) & $670(77.4 \%)$ \\
Mean disease duration (years) & \\
in patients with long-term disease & $9.8 \pm 8.3$ \\
Diagnosis (N) & 162 \\
Colorectal cancer & 168 \\
Rheumatoid arthritis & 56 \\
Systemic lupus erythematosus & 56 \\
Systemic sclerosis & 40 \\
Sjögren's syndrome & 79 \\
Multiple sclerosis & 218 \\
Inflammatory bowel disease & 100 \\
Glaucoma & \\
\hline
\end{tabular}

more than one year were classified as belonging to the "high narcissistic rage" sample. In addition, 76 patients $(38.8 \%)$ among those with disease duration less than one year and 233 (34.8\%) among those with disease duration more than one year were classified as belonging to the "low narcissistic rage" sample.

\section{Narcissistic rage and outcome variables}

Firstly, we examined the relationship between narcissistic rage and outcome variables in the two samples of patients (ie, those with disease duration $<1$ year and those with disease duration $>1$ year). As shown in Table 2 , in medical patients with disease duration less than one year, "narcissistic rage" was slightly but significantly associated with difficulties in interpersonal relationships $(\mathrm{p}<0.05)$ and depressive symptoms, as measured by SCL-90-R ( $\mathrm{p}<0.05)$. No other variable was significantly associated with "narcissistic rage". On the other hand, in patients with disease duration of more than one year, "narcissistic rage" was found to be strongly associated with all outcome variables studied. As shown in Table 2, the higher the narcissistic rage, the higher the interpersonal difficulties and psychiatric symptoms, and the less the rates on all components of HRQOL.

Since in our sample a number of demographic variables was significantly correlated with several parameters of specific disease (such as the gender distribution among the medical illnesses studied), we next performed analyses of covariance (ANCOVAs) with age, gender, and education as covariates, in each sample separately $(<1$ year and $>1$ year). We therefore compared the scores of each outcome variable between patients with "high" versus "low narcissistic rage" in the two subsamples, separately. As shown in Table 3, these analyses showed similar with the previous univariate analyses results, even after controlling for age, gender, and educational level. In the group of patients with disease duration less than one year, patients with "high narcissistic rage" presented more interpersonal difficulties than patients with "low narcissistic rage" ( $p=0.011)$, but there was no other statistically significant difference in all the other outcome variables studied. On the contrary, in patients with disease duration more than one year, patients with "high narcissistic rage" presented significantly higher rates on interpersonal difficulties and on all scales assessing psychiatric symptoms, as well as much lower rates on all the components of HRQOL as compared to their "low narcissistic rage" counterparts ( $\mathrm{p}$-values raging from 0.027 to $<0.0005$ ). 
Table 2 Correlation of "narcissistic rage" with psychosocial variables studied in patients with short-term and long-term physical illness

\begin{tabular}{lll}
\hline Outcome variables & $\begin{array}{l}\text { Patients with disease } \\
\text { duration }<\mathbf{I} \text { year }(\mathbf{N}=196)\end{array}$ & $\begin{array}{l}\text { Patients with disease } \\
\text { duration }>\mathbf{I} \text { year }(\mathbf{N}=\mathbf{6 7 0})\end{array}$ \\
\hline Interpersonal difficulties (IIP) & $0.245^{*}$ & $0.350^{* * *}$ \\
Depressive symptoms (SCL-90) & $0.213^{*}$ & $0.307^{* * *}$ \\
Anxiety symptoms (SCL-90) & 0.073 & $0.285^{* * *}$ \\
Somatization symptoms (SCL-90) & 0.054 & $0.203^{* * *}$ \\
Psychotic symptoms (SCL-90) & 0.153 & $0.345^{* * *}$ \\
Physical symptoms of depression (GHQ) & -0.074 & $-0.133^{* *}$ \\
Depressive symptoms associated with social & -0.040 & $-0.133^{* *}$ \\
relationships (GHQ) & & $-0.219^{* * *}$ \\
General health (WHOQOL-BREF) & 0.058 & $-0.152^{* * *}$ \\
Physical HRQOL (WHOQOL-BREF) & 0.079 & $-0.236^{* * *}$ \\
Mental HRQOL (WHOQOL-BREF) & 0.103 & $-0.227^{* * *}$ \\
Social relationships HRQOL (WHOQOL-BREF) & 0.149 & $-0.188^{* * *}$ \\
Environment HRQOL (WHOQOL-BREF) & 0.118 &
\end{tabular}

Notes: Pearson correlation coefficients, ${ }^{*} \mathrm{p}<0.05$, ${ }^{* *} \mathrm{p}<0.01$, ${ }^{* * *} \mathrm{p}<0.001$.

Abbreviation: $\mathrm{HRQOL}$, health-related quality of life.

\section{Narcissistic rage and interpersonal problems}

Since previous analyses showed an inter-correlation between "narcissistic rage", interpersonal difficulties, and psychological distress, two hierarchical models of multiple regression analyses were next performed in the two samples separately ( $<1$ year and $>1$ year), in order to clarify the unique contribution of each independent variable in the formation of interpersonal difficulties. The dependent variable was the mean score of IIP-40 and the independent variables were the major demographic variables (age, gender, education), "narcissistic rage" and the general symptom index of SCL-90-R.

The results of the two separate hierarchical multiple regression analyses are shown in Table 4 . In both analyses, the SCL-90 global severity index and the "narcissistic rage" fulfilled all the criteria as possible mediators. All VIF were $<2$.

In medical patients with disease duration less than one year (Table 4A), after adjustment for the major demographic variables, addition of "narcissistic rage" (model 2) increased the variance considerably $(p<0.05)$. Addition of SCL-90 Global Severity Index increased the variance by an additional $12.8 \%$ ( $<<0.0005$; model 3 ), but "narcissistic rage" was no longer statistically significant, indicating that psychological distress totally mediates the relationship of "narcissistic rage" with interpersonal difficulties. In the final model, psychological distress was the only variable independently associated with interpersonal difficulties.
In medical patients with disease duration more than one year (Table 4B), after adjustment for the major demographic variables, addition of "narcissistic rage" (model 2$)$ increased also the variance considerably by $13.4 \%(\mathrm{p}<0.001)$. Addition of SCL-90 Global Severity Index further increased the variance ( $<<0.0005$; model 3$)$, but "narcissistic rage" remained also significant, indicating that psychological distress did not mediate the relationship of "narcissistic rage" with interpersonal difficulties. Thus, in the final model, "narcissistic rage" and psychological distress were both independently and significantly associated with interpersonal difficulties.

\section{Discussion}

The results of the present study showed that narcissistic rage, defined as constituted by "omnipotence" and "extrapunitive hostility", is associated with a number of psychosocial parameters in medical patients, especially in those with longer disease duration, confirming thus our hypothesis. Our findings showed that the rage, the narcissistic wrath that emerges in patients with a chronic physical illness, initially affects all patients and is associated with elevated depressive symptoms and difficulties in interpersonal relations. However, in patients with disease duration less than one year, it does not appear to correlate with particular difficulties in other important areas, such as severe psychopathology or impaired quality of life. The patients who are "enraged" soon after the development of the disease do not seem to 
Table 3 Scores in all outcome variables among medical patients with low and high rates on "narcissistic rage" (NR) according to their disease duration (analysis of covariance adjusted for age, gender, and educational level)

\begin{tabular}{|c|c|c|c|c|c|}
\hline \multirow[t]{2}{*}{ Psychosocial variables } & \multirow{2}{*}{$\begin{array}{l}\text { Disease } \\
\text { Duration }\end{array}$} & \multirow{2}{*}{$\frac{\text { Low NR }}{\text { Mean } \pm \text { SE }}$} & \multirow{2}{*}{$\begin{array}{l}\text { High NR } \\
\text { Mean } \pm \text { SE }\end{array}$} & \multirow[t]{2}{*}{$\mathbf{F}$} & \multirow[t]{2}{*}{$\mathbf{p}$} \\
\hline & & & & & \\
\hline \multirow[t]{2}{*}{ Interpersonal problems (IIP mean) } & $<$ I year & $0.58 \pm 0.06$ & $0.79 \pm 0.05$ & 6.6 & 0.011 \\
\hline & $>$ I year & $0.73 \pm 0.04$ & $1.18 \pm 0.04$ & 54.8 & $<0.0005$ \\
\hline \multirow[t]{2}{*}{ Depression symptoms(SCL-90) } & $<$ I year & $0.75 \pm 0.06$ & $0.89 \pm 0.06$ & 2.8 & 0.093 \\
\hline & $>$ I year & $0.81 \pm 0.04$ & $1.20 \pm 0.04$ & 37.8 & $<0.0005$ \\
\hline \multirow[t]{2}{*}{ Anxiety symptoms (SCL-90) } & $<$ I year & $0.40 \pm 0.06$ & $0.55 \pm 0.05$ & 3.3 & 0.069 \\
\hline & $>$ I year & $0.53 \pm 0.05$ & $0.95 \pm 0.05$ & 37.1 & $<0.0005$ \\
\hline \multirow[t]{2}{*}{ Somatization symptoms (SCL-90) } & $<$ I year & $0.75 \pm 0.07$ & $0.79 \pm 0.07$ & 0.2 & 0.642 \\
\hline & $>$ I year & $0.95 \pm 0.05$ & $1.23 \pm 0.05$ & 19.2 & $<0.0005$ \\
\hline \multirow[t]{2}{*}{ Paranoid ideation symptoms (SCL-90) } & $<$ I year & $0.57 \pm 0.08$ & $1.00 \pm 0.07$ & 15.6 & $<0.0005$ \\
\hline & $>1$ year & $0.73 \pm 0.05$ & $1.42 \pm 0.05$ & 95.3 & $<0.0005$ \\
\hline \multirow[t]{2}{*}{ Psychoticism symptoms (SCL-90) } & $<$ I year & $0.33 \pm 0.04$ & $0.43 \pm 0.43$ & 2.8 & 0.096 \\
\hline & $>$ I year & $0.36 \pm 0.03$ & $0.67 \pm 0.03$ & 45.9 & $<0.0005$ \\
\hline \multirow[t]{2}{*}{ Physical symptoms of depression (GHQ-28) } & $<$ I year & $12.8 \pm 0.44$ & $12.4 \pm 0.04$ & 0.5 & 0.487 \\
\hline & $>$ I year & $12.5 \pm 0.29$ & $13.7 \pm 0.26$ & 9.6 & 0.002 \\
\hline Depressive symptoms associated with social & $<$ I year & $15.2 \pm 0.37$ & $14.6 \pm 0.36$ & I.I & 0.289 \\
\hline relationships (GHQ-28) & $>$ I year & $14.3 \pm 0.22$ & $15.1 \pm 0.22$ & 4.9 & 0.027 \\
\hline \multirow[t]{2}{*}{ General health (WHOQOL-BREF) } & $<$ I year & $66.2 \pm 2.5$ & $68.2 \pm 2.2$ & 0.3 & 0.569 \\
\hline & $>$ I year & $66.3 \pm 1.5$ & $58.5 \pm 1.6$ & 11.9 & 0.001 \\
\hline \multirow[t]{2}{*}{ Physical HRQOL (WHOQOL-BREF) } & $<$ I year & $57.1 \pm 2.3$ & $60.7 \pm 2.2$ & 1.3 & 0.260 \\
\hline & $>$ I year & $62.7 \pm 1.3$ & $56.7 \pm 1.3$ & 10.0 & 0.002 \\
\hline \multirow[t]{2}{*}{ Mental HRQOL (WHOQOL-BREF) } & $<$ I year & $63.9 \pm 2.3$ & $67.0 \pm 2.1$ & 0.9 & 0.340 \\
\hline & $>$ I year & $65.3 \pm 1.1$ & $56.3 \pm 1.1$ & 30.5 & $<0.0005$ \\
\hline \multirow[t]{2}{*}{ Social relationships HRQOL (WHOQOL-BREF) } & $<\mathrm{I}$ year & $61.3 \pm 2.8$ & $66.7 \pm 2.5$ & 2.0 & 0.157 \\
\hline & $>$ I year & $62.3 \pm 1.5$ & $53.7 \pm 1.5$ & 15.3 & $<0.0005$ \\
\hline \multirow[t]{2}{*}{ Environment HRQOL (WHOQOL-BREF) } & $<$ I year & $63.1 \pm 2.3$ & $64.7 \pm 2.3$ & 0.3 & 0.596 \\
\hline & $>$ I year & $60.1 \pm 1.0$ & $55.9 \pm 1.0$ & 8.3 & 0.004 \\
\hline
\end{tabular}

Notes: The number of cases with "low narcissistic rage" was 76 for patients with disease duration less than one year and 233 for patients with disease duration more than one year. The respective numbers of cases with "high narcissistic rage were 82 and 237.

Abbreviation: HRQOL, health-related quality of life.

experience a life of poorer quality or increased social and psychological problems compared to the more "relaxed" and dispassionate patients.

On the contrary, those patients with disease duration more than one year (mean duration, 9.8 years) who continue to be "enraged", experience their relations as disturbed, display elevated psychological distress symptoms and report more impaired quality of life, in comparison to their "nonenraged" counterparts. It is worth noting that in patients with disease duration less than one year, psychological distress totally mediates the relationship between narcissistic rage and interpersonal difficulties, whereas in patients with longer disease duration the important role of narcissistic rage in the formation of interpersonal difficulties remained significant even after controlling for psychological distress, indicating that narcissistic rage is associated with interpersonal difficulties independently of psychological distress. This is important, since we and others have found that, in patients with physical and psychosomatic diseases, psychological distress totally mediates the relationship of interpersonal difficulties with several psychosocial parameters, including physical symptoms, pain and physical HRQOL. ${ }^{42-44}$ We found here however that, in patients with longer disease duration, this is not the case with regard to narcissistic rage. In fact, in these patients, the intensity of rage leads to a deterioration of interpersonal relationships to a significant extent, regardless 
Table 4 Hierarchical models of the factors associated with difficulties in interpersonal relationships (IIP-40 mean) in medical patients with disease duration less than one year $(\mathbf{A})$ and more than one year $(\mathbf{B})$

\begin{tabular}{|c|c|c|c|}
\hline Variables & Model I & Model 2 & Model 3 \\
\hline \multicolumn{4}{|l|}{ A. Disease duration less than one year } \\
\hline \multicolumn{4}{|l|}{ Demographics } \\
\hline Age & 0.023 & 0.010 & 0.005 \\
\hline Gender & -0.164 & -0.160 & -0.028 \\
\hline Education & -0.164 & -0.148 & -0.143 \\
\hline “Narcissistic rage” & - & $0.230^{*}$ & 0.106 \\
\hline Psychological distress (SCL-90 GSI) & - & - & $0.404^{* * *}$ \\
\hline Adjusted $\mathrm{R}^{2}$ & 0.029 & 0.073 & 0.201 \\
\hline Incremental adjusted $\mathrm{R}^{2}$ & 0.029 & 0.044 & 0.128 \\
\hline Significance of $F$ change & 0.116 & 0.018 & $<0.0005$ \\
\hline \multicolumn{4}{|l|}{ B. Disease duration more than one year } \\
\hline \multicolumn{4}{|l|}{ Demographics } \\
\hline Age & 0.073 & 0.079 & 0.068 \\
\hline Gender & -0.086 & -0.159 & -0.037 \\
\hline Education & -0.039 & -0.118 & -0.106 \\
\hline “Narcissistic rage” & - & $0.391 * * *$ & $0.183 * * *$ \\
\hline Psychological distress (SCL-90 GSI) & - & - & $0.668 * * *$ \\
\hline Adjusted $\mathrm{R}^{2}$ & 0.001 & 0.135 & 0.489 \\
\hline Incremental adjusted $\mathrm{R}^{2}$ & 0.001 & 0.134 & 0.354 \\
\hline Significance of $\mathrm{F}$ change & 0.622 & $<0.0005$ & $<0.0005$ \\
\hline
\end{tabular}

Notes: Independent variables were sequentially entered in linear regression models in which the dependent variable was the IIP-40 mean score. Values shown are standardized (beta) regression coefficients; ${ }^{p}<0.05 ; *^{*} p 0.01$; ***p $<0.001$.

of other factors studied and, particularly, of psychological distress.

It appears as though in this "reversal" that begins with the appearance of a disease (which triggers the "narcissistic wrath" and serves as a "reminder" of the finite nature of existence and mortality), an ability for "transition" (ie, a proper adaptation to the new situation - the disease - which leads to narcissistic rage's alleviation) results in an integration, with time being the catalyst of this process. On the contrary, when wrath persists (ie, in patients with longer disease duration and high narcissistic rage rates), the consequences appear to be dramatic.

These findings provide initial empirical confirmation of the Kohut's clinical and theoretical postulations on the narcissistic rage alleviation. ${ }^{10,11}$ Patients that understand the original damage (ie, the type of disease and its consequences in their individual and social life) and who are able to shift the aggression in the service of realistic ambition (survival and maintenance of quality of life) are eventually potent to integrate and repair the damaged self. Such a shifting could not occur without significant changes in the self, and hence the matrix out of which the rage arises is transformed. ${ }^{9}$ Anger subsides when the obstacle of frustration is removed or the goal is reached. ${ }^{9,45}$ With reference to the aforementioned part of Homer's Iliad, it seems that the rage that is unleashed from the loss of "Vriseis - Health", initially leads to a withdrawal from the battlefield (withdrawal from interpersonal relationships and a mild sadness). Following that, the doctors, the exhausted diagnostic procedures, the operations and the therapeutic efforts, all serve as "reminders" that the future (ie, the perishable nature of our existence, and death) is already past. In other words, the sick body reminds exactly what the images of the dead Patroclus (dressed as Achilles) and Hector (dressed as Achilles, as well) remind to Achilles. The disease "wears" the shell-armor of the image of our healthy self. It is the mortal image of ourselves: the dead Patroclus-Achilles.

If this "reminder" (the disease) serves as a "call for a transition", the ground will be fertile for integration and compassion. After initial mourning and deterioration in interpersonal relationships, the difficulties subside and the quality of life is restored. Reconciliation and "friendship" with the "enemies" (ie, the doctors, who are also "reminders" of the disease) replaces rage; "friendship" replaces arrogance, 
and the "meeting" of the two "enemies" is turned into an "entourage", one accompanies the other on the road toward his destiny, with concern and compassion. On the contrary, when arrogance persists, all sides are defeated.

Our study, in our effort to integrate the echo of an ancient Greek epos into the current knowledge about illness and coping with illness, provides only "fragments of reality" and consequently includes a number of theoretical as well as methodological limitations.

The main limitation of our study lies in the composition of narcissistic rage scale, which is the result of the combination of components that belong to different questionnaires. Although various measures of narcissism have been developed, to the best of our knowledge to date there has been no validated instruments for measuring narcissistic rage. "Narcissistic Personality Inventory", 7 which has received the most empirical attention to date, is regarded a measure for the general construct of narcissism as well as of seven first order components, identified as authority, exhibitionism, superiority, vanity, exploitativeness, entitlement, and selfsufficiency. No subscale, however, is relevant to "narcissistic rage", which was the cornerstone of our hypothesis. We therefore constructed a scale reflecting the external-directed aggressive reaction to frustrating occurrences on the part of the "omnipotent" individual, by merging the two components of DSQ and HDHQ. Although the combination of "extrapunitive" hostility and "omnipotence" defence by themselves do not answer clinical questions with regard to fixation and rigidity of narcissistic traits or states, our findings underpin its theoretical foundation and support its usefulness in measuring this specific aspect of narcissism. From a statistical point of view, although our initial examination revealed that the new variable showed a high internal consistency (which reflects a satisfactory clustered structure of the scale, given that it comprised only two components), further study of its psychometric properties is needed to confirm its reliability and validity. Future studies to test the stability of the scale over time (test-retest reliability) as well as its factor structure, criterion validity and concurrent validity should be conducted in order to detect whether the new scale measures what is designed to measure, ie, narcissistic rage.

The cross-sectional design of our study prevents us for generalizing our findings, since it is not possible to examine whether or not the change in narcissistic rage over time in each individual patient has a similar impact on outcome variables for this specific patient. Thus, the findings need to be replicated in prospective longitudinal studies, in order to assess the "movement" of "narcissistic rage" in each individual patient across time intervals. In this way we might be able to test whether or not the tendency to narcissistic rage or its underlying "matrix" leads to severe mental deterioration with time, or to some form of burnout. Moreover, the drawback of using only self-report measures means that we cannot refute the criticism that an underlying response style might have led to our results. Thus, in addition to the aforementioned suggested longitudinal studies, future clinical, psychoanalytic studies could also complement the findings of the present study with other types of significant and clinically useful inquiries.

On the other hand, we recruited a large number of patients, we did used well recognized instruments for all our measures, we had reasonably high response rates and there were no statistically significant differences between responders and nonresponders. In addition, our secondary and tertiary hospital provides care to the majority of the patients with these diseases of the catchment area suggesting that we recruited a representative sample of people with these severe chronic medical conditions. However, we cannot exclude the possibility that particularly severe patients were under-represented as such patients might be in hospital or unable to join the study. In addition to this, there was remarkable variability among the disease categories studied and, taking into consideration the focus of the present study, the issues inherent in one disease with respect to patients' finite nature of existence and mortality are different than similar issues in another disease. For example, although glaucoma may result in blindness (ie, a severe loss), it is not life-threatening, whereas colorectal cancer is. Since patients are expected to react differently if the illness is life-threatening or only nuisance (even with severe loses) introducing thus a sampling bias in our study, our results must be interpreted with caution. Although the emphasis of our study was on chronic illness, in general, future clinical, psychoanalytic studies are needed to illuminate the subjective implications of narcissistic rage for people with specific, either life-threatening or not, physical diseases.

In conclusion, our results showed that narcissistic rage has a rather minor impact on some psychosocial parameters in patients with disease duration less than one year, indicating that the rage is rather part of a "normal" mourning process after the appearance of a severe medical illness. On the contrary, in those patients with longer disease duration in whom the narcissistic rage insists, the interpersonal relationships and quality of life are more impaired and the rates on a number of psychological distress symptoms are elevated, indicating 
that narcissistic rage could actually be regarded as an "Achilles' Heel" for patients with long-term chronic physical illness. These findings may have important clinical implications.

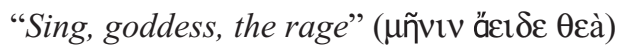

$$
\begin{aligned}
& \text {-Homer's Iliad, first line }
\end{aligned}
$$

In this first phrase of Iliad, the poet asks the goddess to "sing the rage", secretly underscoring the great importance of "rage" in humans' life. Based on the results of the present study, it could be suggested that, in therapy, emphasis should be given on the significance of "rage".

The first months after the appearance of a severe physical illness, the consequences of rage are rather moderate. At this stage, rage may even be useful. In a Kleinian perspective, the primitive aggression and the creative actions are inseparable and they are necessary for the oncoming developments and the ability to change. ${ }^{12}$ At this stage, rage could be the pace of a continuous alternation between the catastrophic attack against the object and the object's restoration, promoting the building of a bridge over the gap between the persecuting and the caring object, and this promotes the foundation of hope. ${ }^{12}$ Therefore, the patients' depressive symptoms at this stage should be respected, since they might represent hallmarks of a normal mourning process that helps the individual to develop a capacity for integration through a "repetitive circle of disaster and restoration". ${ }^{46}$

On the other hand, these depressive feelings could also serve as indicators of active underlying narcissistic rage, and therapists should focus their efforts on the elaboration of these "depressive" feelings, in order to help patients to deal with the underlying feelings of rage and to further promote this "maturation" process (ie, the alteration between disaster and restoration) by working through depressive anxieties. ${ }^{12}$ In a Kohutian perspective, the therapist should adopt an "empathetic" stance, serving as "a mirroring object" for these patients, ${ }^{47}$ taking into consideration that the lack of self-cohesiveness in narcissism is regarded as a result of the parents' empathic failure, including a failure of mirroring. ${ }^{45}$ In these ways, the acknowledgment of the primitive aggressiveness could lead patients to compassion and concern, after the use of omnipotence as a defense against depressive feelings has diminished. ${ }^{48}$

In the early years after the establishment of a severe physical disease, however, rage becomes rather disastrous, affecting several aspects of the patients' psychosocial life, as our results have shown. At this time, therefore, physicians and therapists ought to focus on the alleviation of the rage in order to prevent further deterioration of the patients' individual and social life.

Respecting rage as a necessary prerequisite for the capacity to express compassion in the first stages of a disease and helping the patient to alleviate the rage later, may assist the patient's capacity for a "transition" from the primitive narcissistic thesis to an integration and repair of the damaged self, so that he/she might be able to live the unavoidable condition of being human.

\section{Disclosures}

The authors report no conflicts of interest in this work.

\section{References}

1. Melville H. Moby Dick or the Whale. New York, NY: Modern Library Edition; 1982 (1851).

2. Freud S. Psychoanalytic notes upon an autobiographical account of a case of paranoia (Dementia Paranoides). Vol. 12. London, UK: Hogarth Press; 1911.

3. Gomez EA. The Narcissus legend, the white whale, and Ahab's narcissistic rage: a self-psychological perspective. $J$ Am Acad Psychoanal. 1990;18:644-653.

4. Freud S. On narcissism: An introduction. Vol. 14. London, UK: Hogarth Press; 1914.

5. Freud S. Instincts and their vicissitudes. London, UK: Hogarth Press; 1915. p. 14:111-140.

6. Sandler J, Person ES, Fonagy P, editors. Freud's On Narcissism: An Introduction. New Haven, CT: Yale University Press; 1991.

7. Raskin R, Terry H. A principal-components analysis of the Narcissistic Personality Inventory and further evidence of its construct validity. J Pers Soc Psychol. 1988;54(5):890-902.

8. Kernberg O. Borderline conditions and pathological narcissism. New York, NY: Jason Aronson; 1975.

9. Terman DM. Aggression and Narcissistic rage: A clinical elaboration. Ann Psychoanal. 1974;3:239-255.

10. Kohut H. Thoughts on Narcissism and Narcissistic Rage. Psychoanal Study Child. 1972;27:360-400.

11. Kohut H. The Analysis of the Self. New York, NY: International Universities Press; 1971.

12. Arvanitakis K. Psychoanalysis and Homer's Epic [In Greek]. Athens, Greece: Icaros ed. 2008.

13. Rouse WHD. The Iliad. 1938. New York, NY: Signet Classics Editions; p.11.

14. Homer. The Iliad. Richmond Lattimore, translator. Chicago, IL: University of Chicago Press; 1951. p. 1:181-187.

15. American Joint Committee on Cancer. Colon and Rectum. Philadelphia, PA: Lippincott-Raven Publishers; 2002.

16. Compton CC, Fielding LP, Burgart LJ, et al. Prognostic factors in colorectal cancer. College of American Pathologists Consensus Statement, 1999. Arch Pathol Lab Med. 2000;124(7):979.

17. American Rheumatism Association Diagnostic and Therapeutic Committee: Subcommittee for scleroderma criteria: Preliminary criteria for the classification of systemic sclerosis (scleroderma). Arthritis Rheum. 1980;23:581-590.

18. Arnett FC, Edworthy SM, Bloch DA, et al. The American Rheumatism Association 1987 revised criteria for the classification of rheumatoid arthritis. Arthritis Rheum. 1988;31(3):315-324.

19. Hochberg MC. Updating the American College of Rheumatology revised criteria for the classification of systemic lupus erythematosus Arthritis Rheum. 1997;40(9):1725.

20. McDonald WI, Compston A, Edan G, et al. Recommended diagnostic criteria for multiple sclerosis: guidelines from the International Panel on the diagnosis of multiple sclerosis. Ann Neurol. 2001;50:121-127. 
21. Pappa C, Hyphantis T, Pappa S, et al. Psychiatric manifestations and personality traits associated with compliance with glaucoma treatment. J Psychosom Res. 2006;61(5):609-617.

22. Goldberg DP, Hillier VF. A scaled version of the General Health Questionnaire. Psychol Med. 1979;9:139-145.

23. Garyfallos G, Karastergiou A, Adamopoulou A, et al. Greek version of the General Health Questionnaire: accuracy of translation and validity. Acta Psychiatr Scand. 1991;84:371-378.

24. Derogatis LR. SCL-90-R: Administration, scoring, and procedure manual. 3rd Ed. Minneapolis, MN: National Computer Systems; 1994.

25. Donias S, Karastergiou A, Manos N. Standardization of the symptom checklist-90-R rating scale in a Greek population (in Greek with English abstract). Psychiatriki. 1991;2:42-48.

26. Riding A, Cartwright A. Interpreting the Inventory of Interpersonal Problems: Subscales based on an interpersonal theory model. $\mathrm{Br} \mathrm{J} \mathrm{Med}$ Psychol. 1999;72:407-420.

27. Horowitz LM, Rosenberg SE, Baer BA, Ureno G, Villasenor VS. Inventory of interpersonal problems: Psychometric properties and clinical applications. J Consul Clin Psychol. 1988;56:885-892.

28. Caine TM, Foulds GA, Hope K. Manual of Hostility and Direction of Hostility Questionnaire. London, UK: University of London Press; 1967.

29. Angelopoulos NV, Drosos AA, Moutsopoulos HM. Psychiatric symptoms associated with scleroderma. Psychother Psychosom. 2001;70:145-150.

30. Hyphantis TN, Triantafillidis JK, Pappa S, et al. Defense mechanisms in inflammatory bowel disease. J Gastroenterol. 2005;40:24-30.

31. Hyphantis TN, Tsifetaki N, Siafaka V, et al. The impact of psychological functioning upon systemic sclerosis patients' quality of life. Semin Arthritis Rheum. 2007;37(2):81-92.

32. American Psychiatric Association. Diagnostic and Statistical Manual of Mental Disorders. 4th ed. Washington DC: American Psychiatric Press; 1994.

33. Bond M. An empirical study of defense styles: the Defense Style Questionnaire. In: Vaillant GE, editor. Ego Mechanisms of Defense: A Guide for Clinicians and Researchers. Washington, DC: American Psychiatric Press; 1992. p. 139-140.

34. Paika V, Almyroudi A, Tomenson B, et al. Personality variables are associated with colorectal cancer patients' quality of life independent of psychological distress and disease severity. Psychooncology. 2009; DOI:10.1002/pon.1563.
35. WHOQOL Group. Development of the World Health Organization WHOQOL-BREF quality of life assessment. The WHOQOL Group. Psychol Med. 1998;28(3):551-558.

36. Skevington SM, Lotfy M, O'Connell KA. WHOQOL Group. The World Health Organization's WHOQOL-BREF quality of life assessment: psychometric properties and results of the international field trial. A report from the WHOQOL group. Qual Life Res. 2004;13(2):299-310.

37. Taylor WJ, Myers J, Simpson RT, McPherson KM, Weatherall M. Quality of life of people with rheumatoid arthritis as measured by the World Health Organization Quality of Life Instrument, short form (WHOQOL-BREF): score distributions and psychometric properties. Arthritis Rheum. 2004;51(3):350-357.

38. Ginieri-Coccossis M, Triantafillou E, Antonopoulou V, Tomaras B, Christodoulou G. Quality of life in relation to WHOQOL-100 questionnaire (in Greek). Athens, Greece: Beta Medical Arts; 2001.

39. Altman DG. Practical Statistics for Medical Research. London, UK: Chapman and Hall; 1991.

40. Baron RM, Kenny DA. The moderator-mediator variable distinction in social psychological research: conceptual, strategic, and statistical considerations. J Pers Soc Psychol. 1986;51:1173-1182.

41. Miles J, Shevlin M. Applying regression and correlation. London, UK: Sage Publications; 2003. p. 165-191.

42. Hyphantis T, Guthrie E, Tomenson B, Creed F. Psychodynamic interpersonal theraphy and improvement in interpersonal difficulties in people with severe irritable bowel syndrome. Pain. 2009; Jul 28. [Epub ahead of print].

43. Howard I, Turner R, Olkin R, Mohr DC. Therapeutic alliance mediates the relationship between interpersonal problems and depression outcome in a cohort of multiple sclerosis patients. J Clin Psychol. 2006;62(9):1197-1204.

44. Nickel MK, Krawczyk J, Nickel C, et al. Anger, interpersonal relationships, and health-related quality of life in bullying boys who are treated with outpatient family therapy: a randomized, prospective, controlled trial with 1 year of follow-up. Pediatrics. 2005;116(2):e247-e254.

45. Kohut H. Does Analysis Cure? Chicago, IL: University of Chicago Press; 1984.

46. Winnicot DW. Collected Papers. London, UK: Tavistock Publications; 1958. p. 270

47. Gabbard GO. Psychodynamic Psychiatry in Clinical Practice, 3rd ed. Arlington, VA: American Psychiatric Press; 2000.
Patient Preference and Adherence

\section{Publish your work in this journal}

Patient Preference and Adherence is an international, peer-reviewed, open access journal that focusing on the growing importance of patient preference and adherence throughout the therapeutic continuum. Patient satisfaction, acceptability, quality of life, compliance, persistence and their role in developing new therapeutic modalities and compounds to

\section{Dovepress}

optimize clinical outcomes for existing disease states are major areas of interest. This journal has been accepted for indexing on PubMed Central. The manuscript management system is completely online and includes a very quick and fair peer-review system. Visit http://www.dovepress.com/ testimonials.php to read real quotes from published authors. 